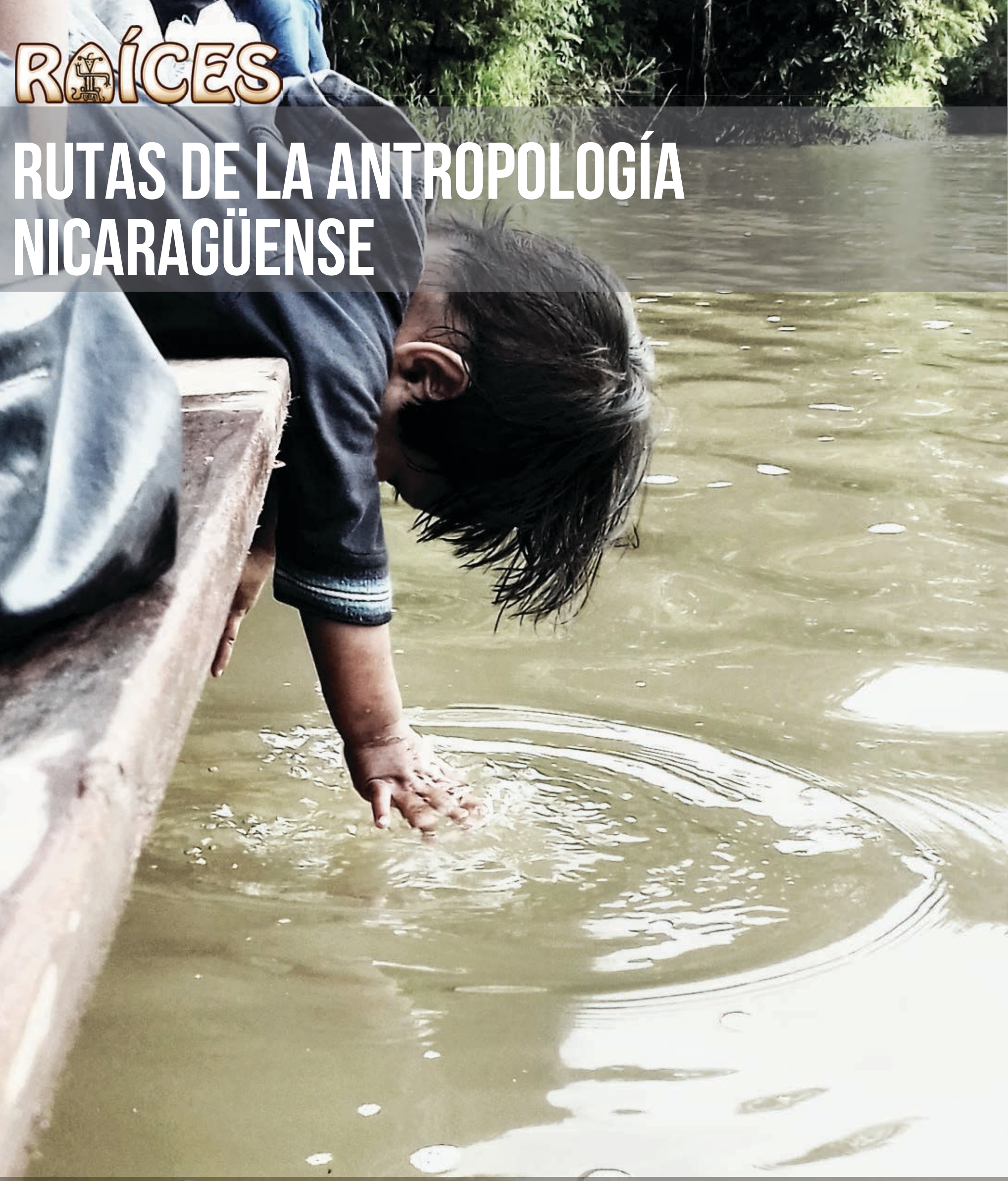

Niño mayangna jugando con las aguas del río Bocay. Está viajando en bote a motor junto a su madre, desde Ayapal rumbo a Amak, comunidad Mayangna-Sauni Bu, al norte de Jinotega.

(Foto: Silke Pérez) 


\title{
Veinte años de Antropología en Nicaragua
}

\author{
Gloria Argentina López Alvarado \\ Elvira Maritza Andino \\ María Dolores Álvarez Arzate
}

$\mathrm{E}$

1 origen del Departamento de Antropología se debe buscar en diciembre de 1991, cuando se realizó el primer curso de Métodos Antropológicos impartido por antropólogos y antropólogas comprometidos con las poblaciones y comunidades de nuestros pueblos latinoamericanos. Éste fue el punto de partida del grupo fundacional del actual Departamento de Antropología, cuya Carrera de Antropología Social fue aprobada por el Consejo Universitario de la UNAN Managua en octubre de 1994.
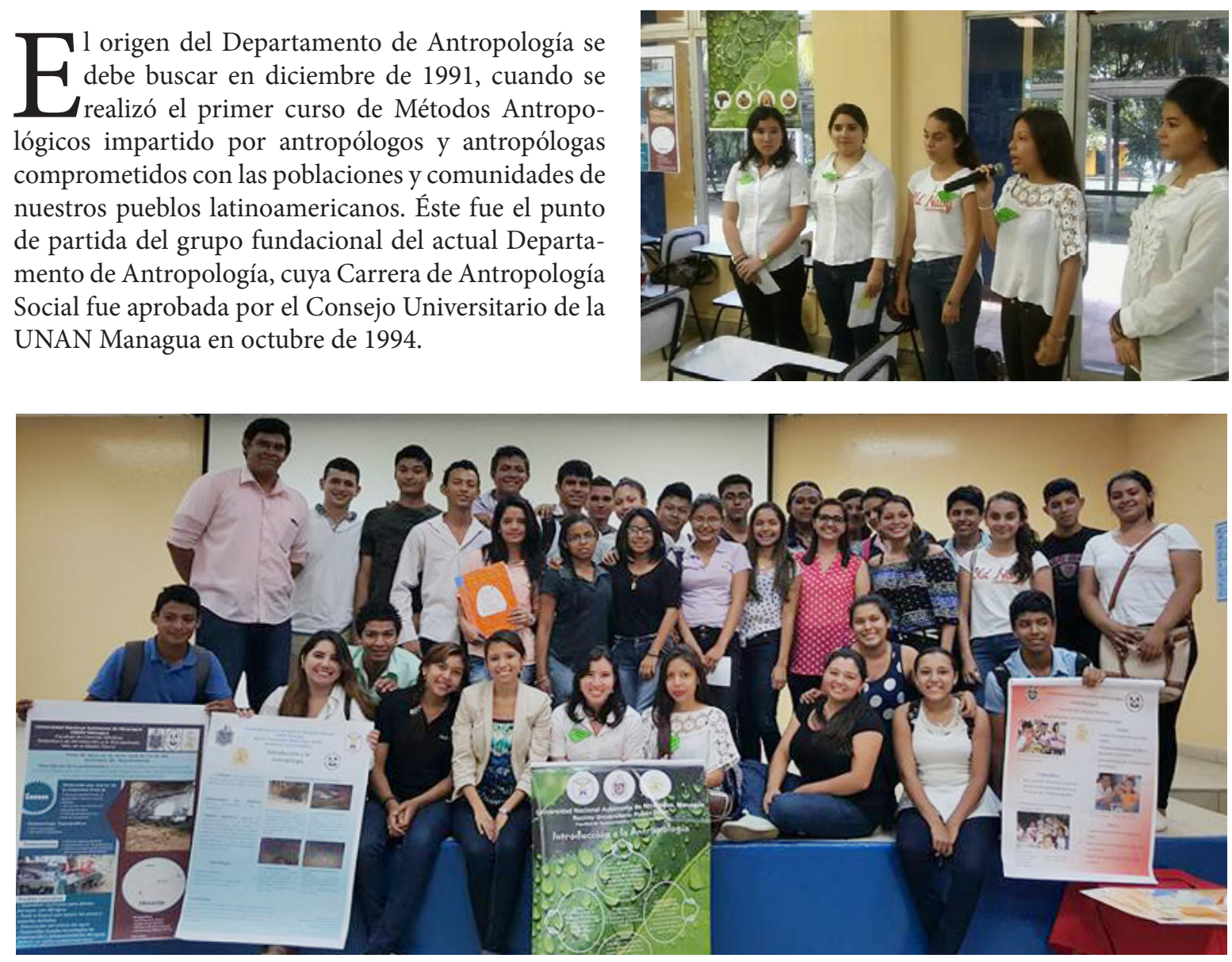

Examen de Introducción a la Antropología. Los estudiantes de distintas carreras de las Facultades de la UNANManagua presentan sus investigaciones etnográficas a través de póster y brochure. I Semestre 2016 (Fotos: Departamento de Antropología).
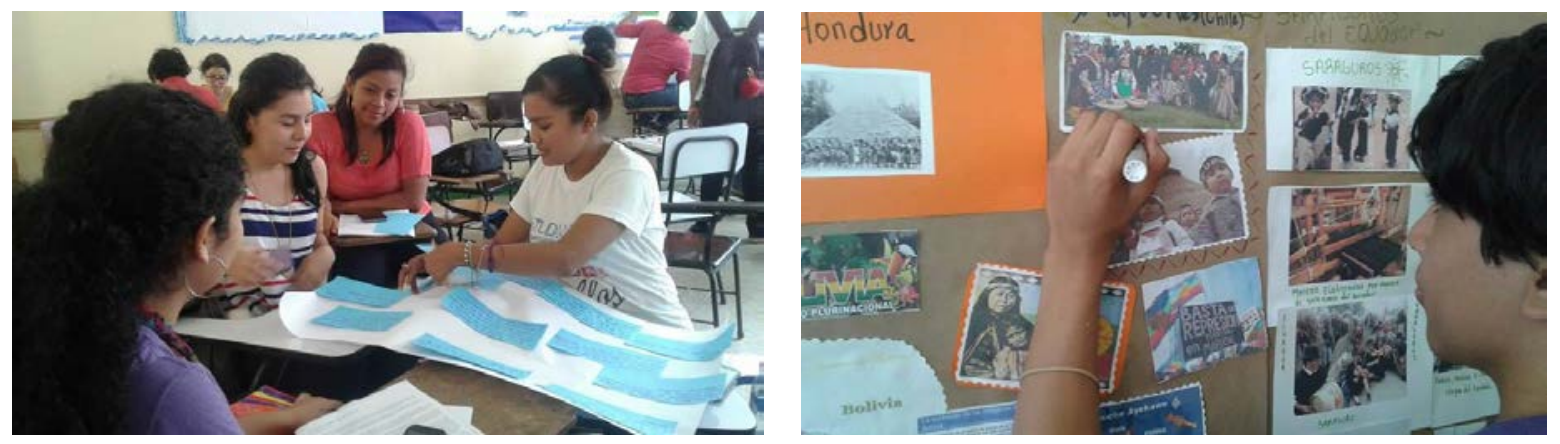

Trabajos en sub-grupos en el aula de clase. Estudiantes de primero y tercer año de la Carrera de Antropología Social. I y II Semestre 2016 (Fotos: Departamento de Antropología) 
El grupo fundador estuvo compuesto por treinta profesionales, la mayor parte en el ejercicio de la docencia universitaria en la UNAN Managua, quienes participaron, en diciembre de 1992, en el Seminario sobre Antropología Rural y escribieron colectivamente el libro "El Universo de la Tierra. Las culturas campesinas en el Pacífico y Centro de Nicaragua" (1993).

Contribuyen a su fundación, la inspiración en los valores y principios de la Revolución Popular Sandinista, entre los que destaca el reconocimiento a la multiculturalidad, la solidaridad, la búsqueda de nuevas formas de abordar el Buen Vivir con respeto a los saberes ancestrales, la tradición oral y dignidad de las identidades culturales.

La Directora del Departamento de Antropogía, Dra. Maritza Andino, participando como alfabetizadora en la Cruzada Nacional de Alfabetización, promovida en el marco de la Revolución Popular Sandinista. Marzo de 1980 (Foto: Elvira Maritza Andino)

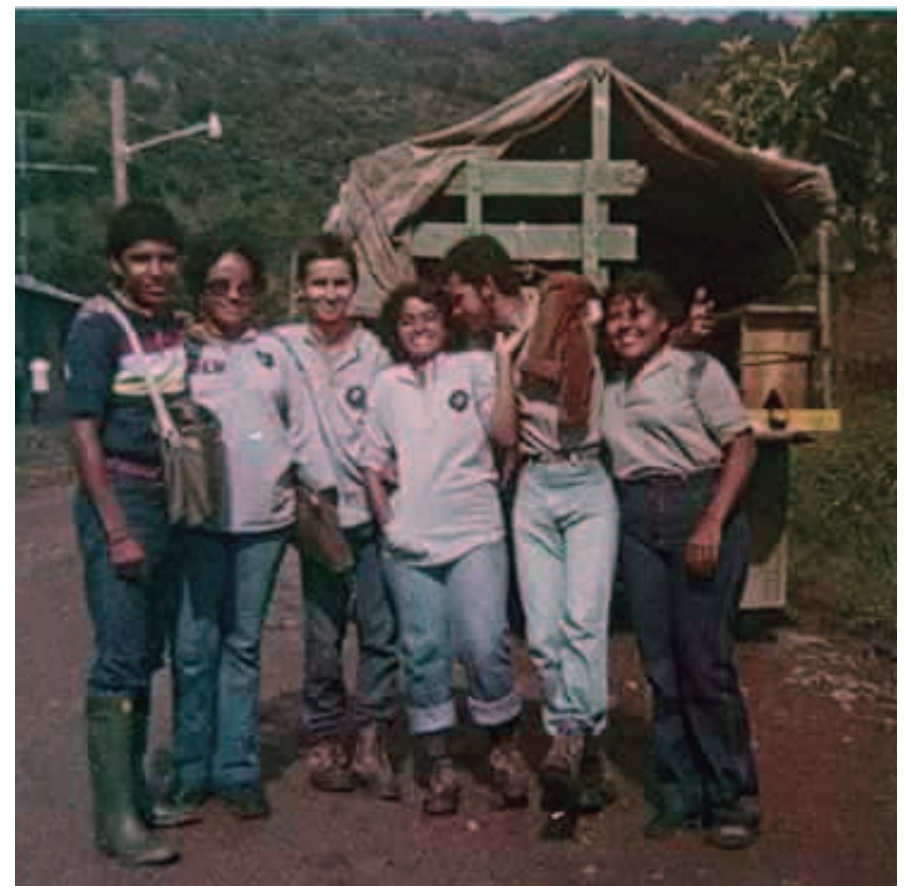

La Coordinadora de Investigación Estudiantil, Maestra Gricelda Téllez Vado, al centro, con un grupo de alfabetizadores durante la Cruzada Nacional de Alfabetización. Marzo de 1980 (Foto: Juana Gricelda Téllez Vado).

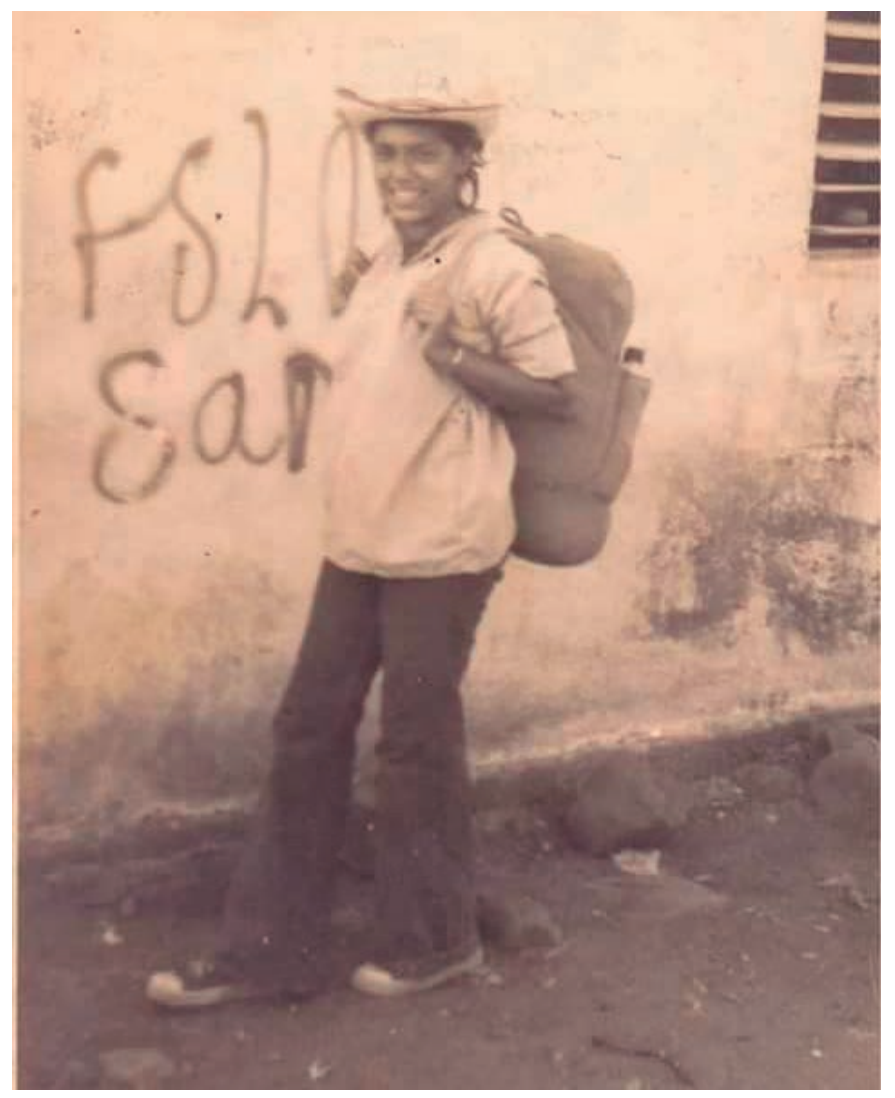


La primera década de esfuerzos por la construcción de unas antropologías propias en Nicaragua se relaciona con la fundación de la Red Centroamericana de Antropología en 1994, que desarrolla sinergias y resistencias académicas en un contexto marcado por la implementación de las políticas neoliberales deshumanizantes.

En el periodo 1993-1997, con el propósito de desarrollar la formación en el nivel de posgrado, se intensificaron los intercambios académicos y se profundizaron lazos de colaboración con universidades y centros de investigación de nivel internacional en las distintas especialidades de la Antropología, y es así que los docentes de la Antropología Social en Nicaragua recibieron formación con académicos de la Universidad de Zúrich, Universidad de Viena, Universidad de La Habana, Universidad Autónoma de México Iztapalapa.

Más adelante, como miembros de la Red Centroame- ricana de Antropología se ampliaron las alianzas con académicos de universidades de México, Guatemala, Honduras, El Salvador, Costa Rica y Panamá. De tal manera que, diez años después de la creación de la $\mathrm{Ca}$ rrera de Antropología Social, se realizó en Managua el V Congreso Centroamericano de Antropología (23 al 27 de febrero de 2004), con una participación extraordinaria de académicos y estudiantes con más de 200 ponencias y 500 inscripciones.

En el espacio la Red Centroamericana de Antropología el liderazgo del Departamento de Antropología se confirma en el cargo de la Secretaria Ejecutiva de la Red por dos periodos consecutivos 2012-2014 y 20152017.

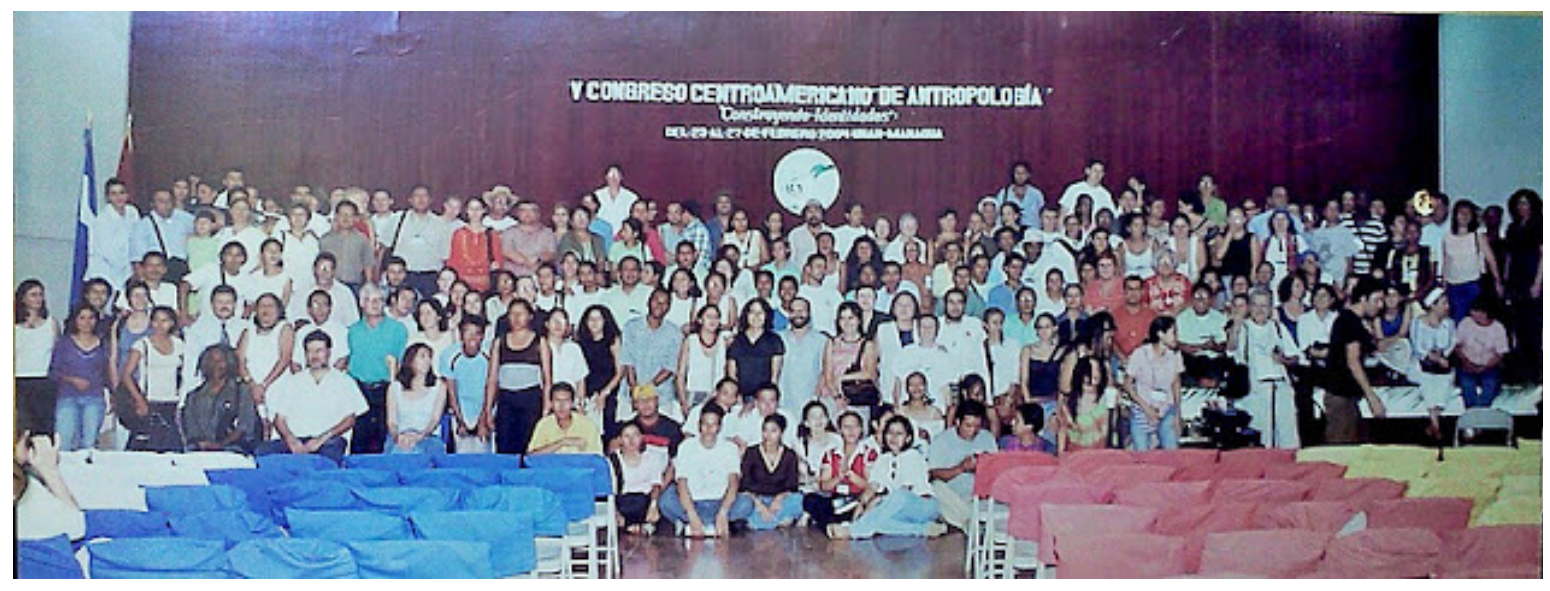

V Congreso Centroamericano de Antropología, 23-27 febrero de 2004. UNAN-Managua

(Foto: María Dolores Alvarez Arzate) 


\section{Raíces}

Revista Nicaragüense de Antropología. Año 1 No. 1/2017

La Carrera de Antropología Social tuvo su primer Plan de Estudios en 1993 y como parte de los procesos generales de modernización de la UNAN Managua ha experimentado dos procesos de transformación curricular de 1999 y 2013.

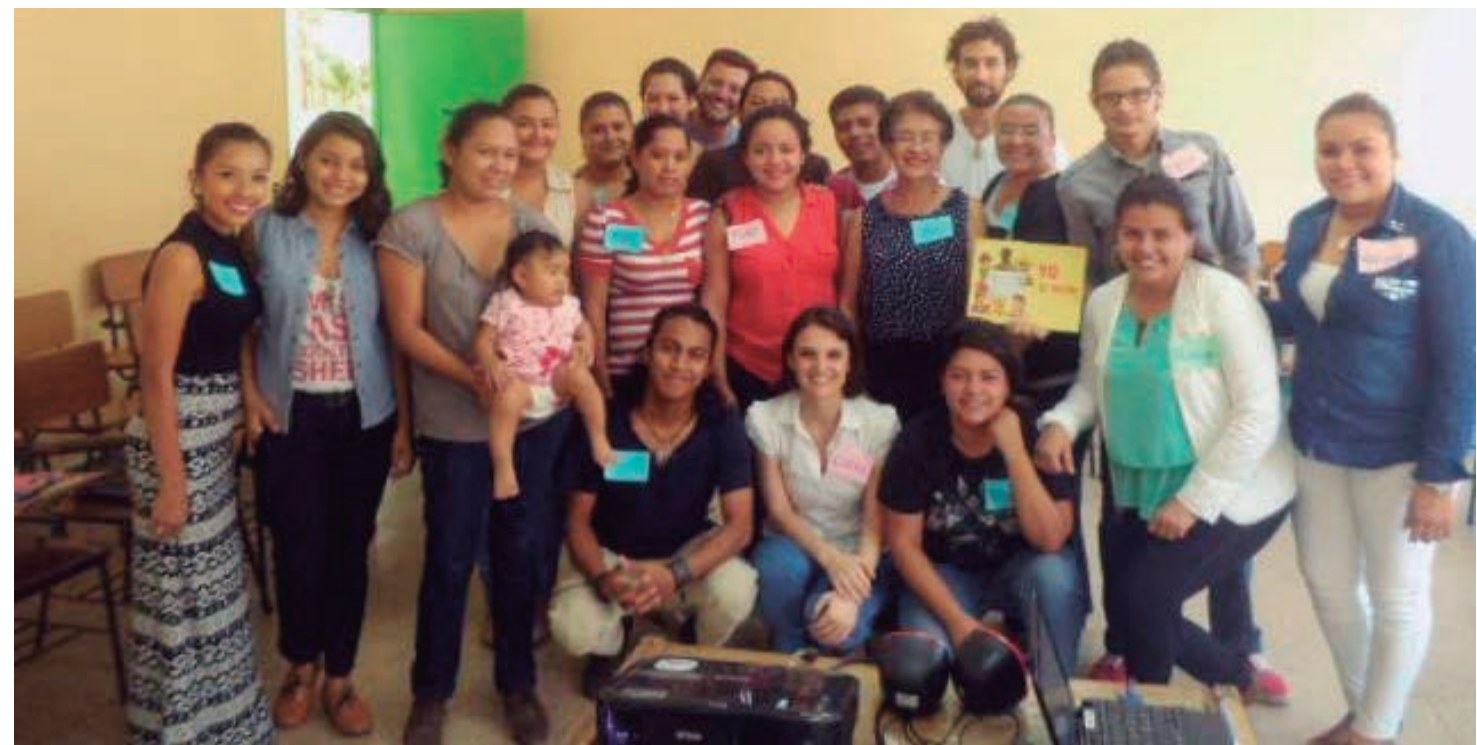

Alfabetizadores de ayer y de hoy. Conversatorio con las alfabetizadoras de los 80, maestra Gricelda Téllez Vado y licenciada Lilia Alfaro Páez y con las jóvenes alfabetizadoras Naraya Berríos y Valeria Lindo, quienes participaron en la campaña educativa De Martí a Fidel, realizada con el reconocido método cubano Yo sí puedo, en el periodo 2007-2009. Actividad realizada con el grupo de cuarto año de la Carrera de Antropología Social. Asignatura: Antropología de la Educación. Agosto de 2015 (Foto: Cecilia Costa).

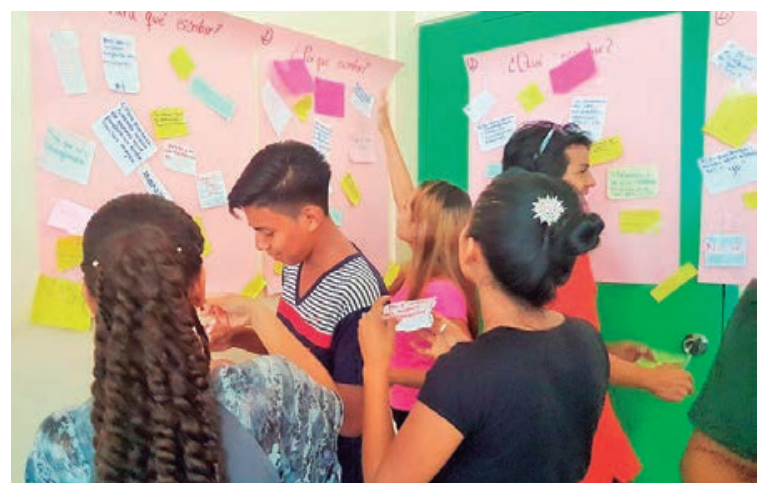

Estudiantes de la Carrera de Antropología Social profundizan sus conocimientos sobre Técnicas de Redacción Científica a través de Talleres de fortalecimiento de la Investigación Estudiantil. I Semestre 2016.

(Fotos: Departamento de Antropología)

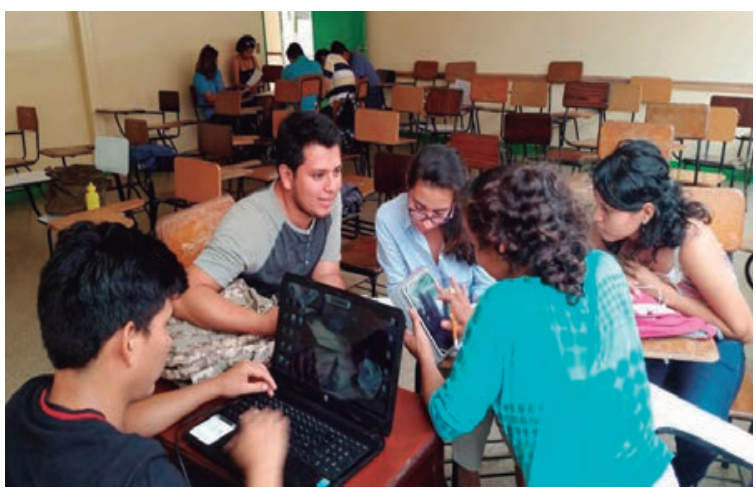

Estudiantes de tercer año de la Carrera trabajando en subgrupos. Año académico 2016.

(Fotos: Departamento de Antropología) 
El Departamento de Antropología, desde sus inicios, ha promovido la investigación como parte de la formación desde el primer año de estudios, lo que ha fructificado en la participación en las Jornadas Universitarias de Desarrollo Científico (JUDC) a nivel facultativo, a nivel central de la UNAN Managua y a nivel nacional en la Expo-Ciencia promovida por el Consejo Nacional de Universidades (CNU) y el Consejo Nacional para la Ciencia y Tecnología (CONICYT).

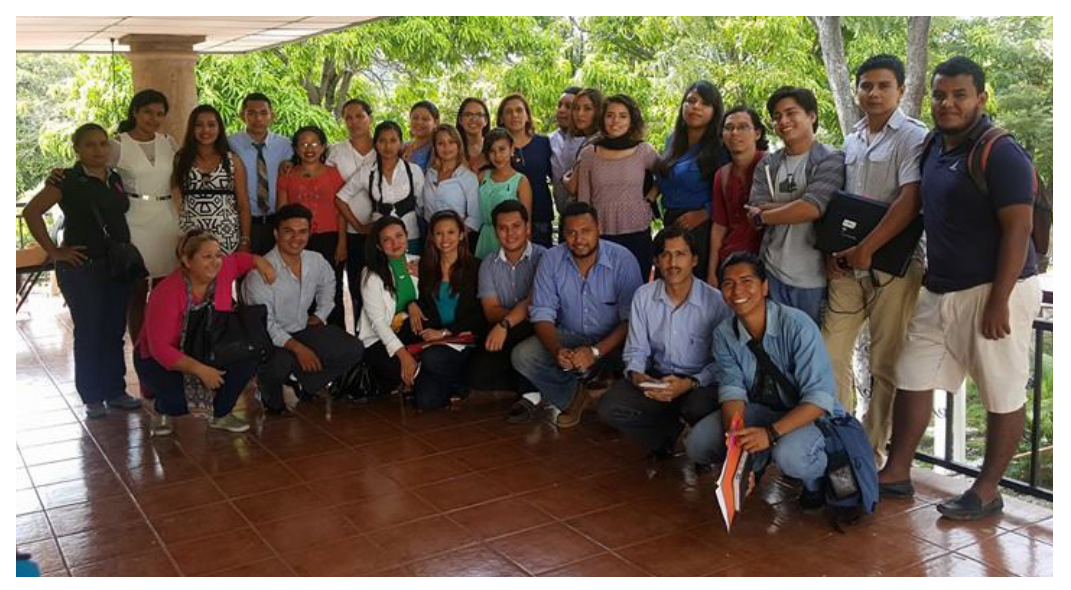

Jornadas Universitarias de Desarrollo Científico, JUDC. Edición 2015 y 2016 (Foto: Departamento de Antropología)
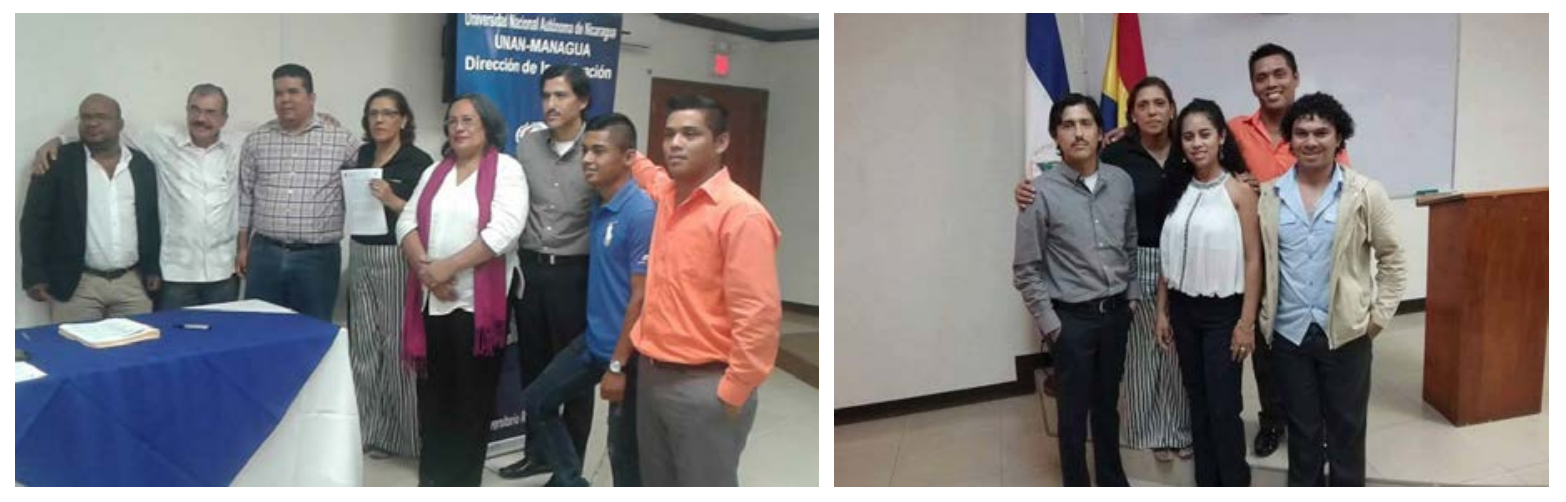

Delegación del Departamento de Antropología recibe financiamiento para los dos proyectos ganadores de los Fondos Concursables de Innovación, edición 2016: Aplicación multimedia para la asignatura de introducción a la Antropología (INTRA) y NATUGRIP, remedio natural contra la gripe (Foto: Departamento de Antropología)

El Departamento de Antropología participa en la Expociencia $\mathrm{Na}$ cional, organizada por el Consejo Nicaragüense de Ciencia y Tecnología (CONICYT), presentando dos proyectos de innovación. En la foto, la delegación del Departamento de Antropología, con el vicepresidente de la República, general en retiro Omar Halleslevens y el Vicerrector de la UNAN-Managua, maestro Jaime Lowery

(Departamento de Antropología).

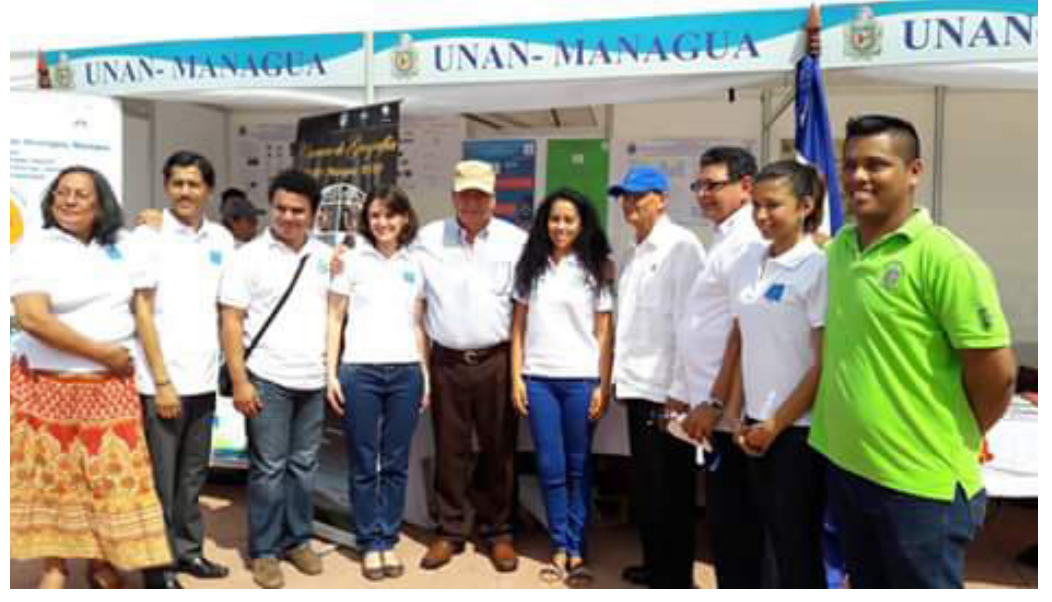




\section{Raíces}

Revista Nicaragüense de Antropología. Año 1 No. 1/2017

Con el impulso propio de sus docentes y coherente con la visión institucional, se han implementado programas de crecimiento estudiantil tales como los alumnos ayudantes, el voluntariado social, el desarrollo de proyectos de innovación y emprendimiento.

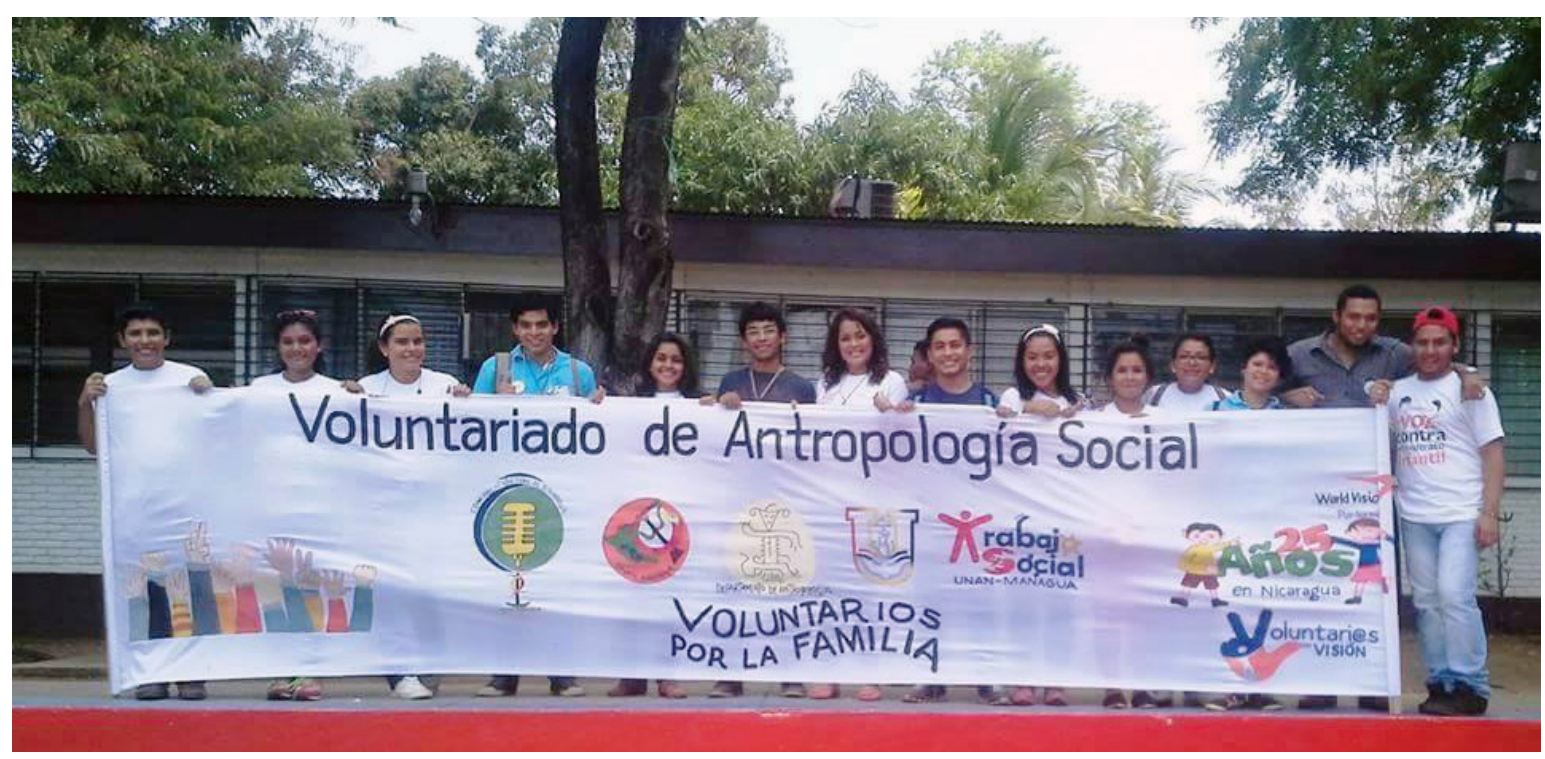

Experiencias de Voluntariado social coordinadas por el Departamento de Antropología Social. Año académico 2014 (Foto: Departamento de Antropología)

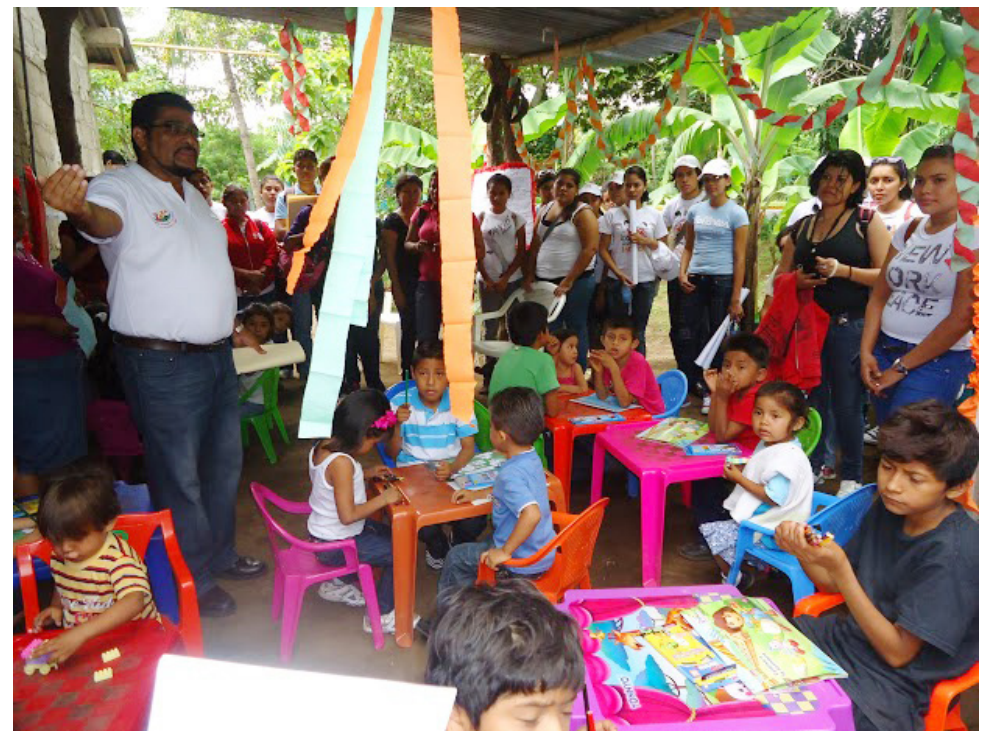

Voluntarios del Departamento de Antropología Social colaboran con la ONG Visión Mundial, apoyando en proyectos socio-educativos de comunidades rurales. Año académico 2014

(Foto: Departamento de Antropología) 
Al concluir 2016, se contabilizan 174 monografías defendidas, cuyos autores y autoras egresados de 17 cohortes, se encuentran laborando en diferentes instituciones de Gobierno, Alcaldías, Organismos No Gubernamentales, proyectos de desarrollo comunitario y trabajando por cuenta propia en iniciativas emprendedoras.
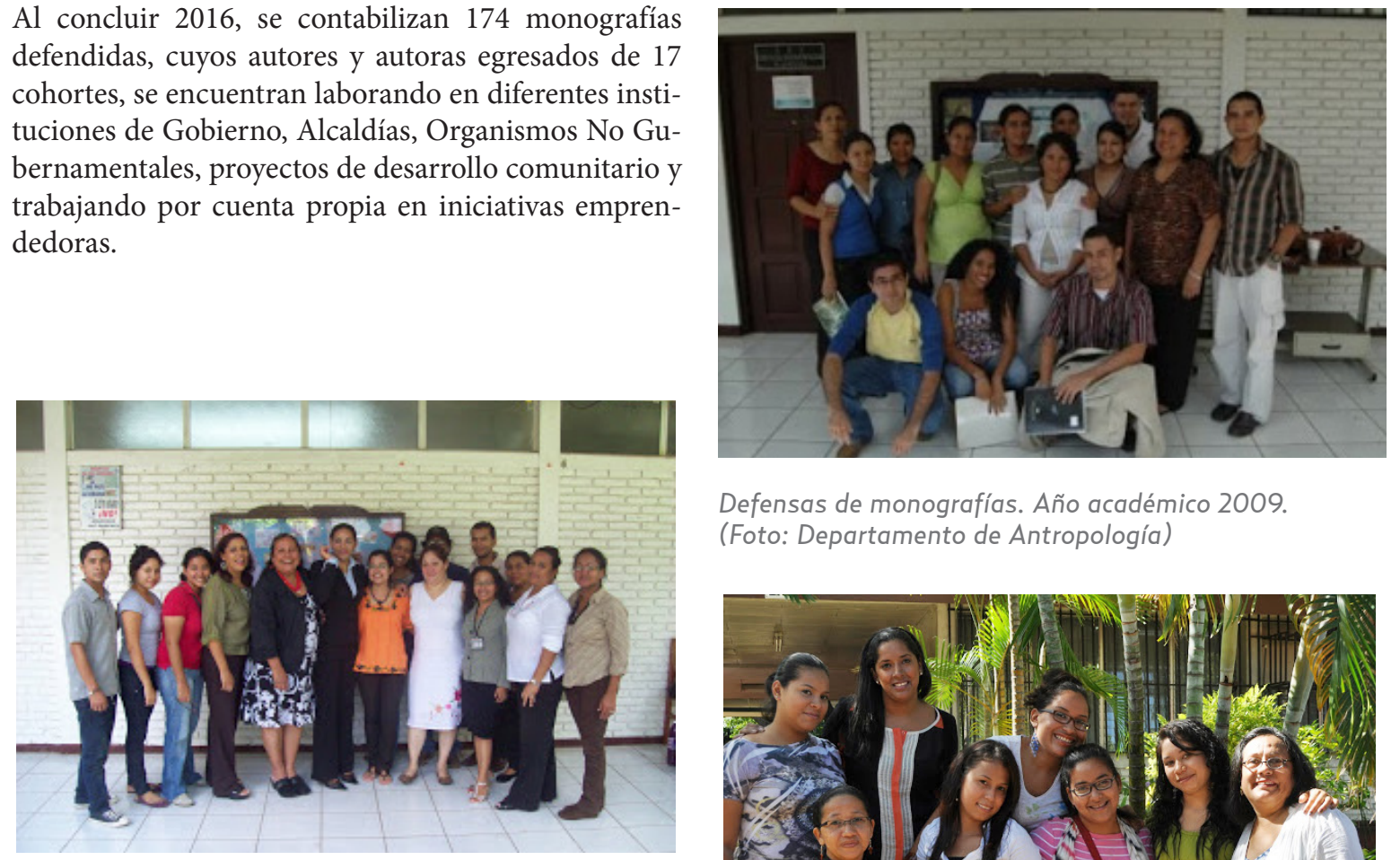

Defensas de monografías. Año académico 2009. (Foto: Departamento de Antropología)

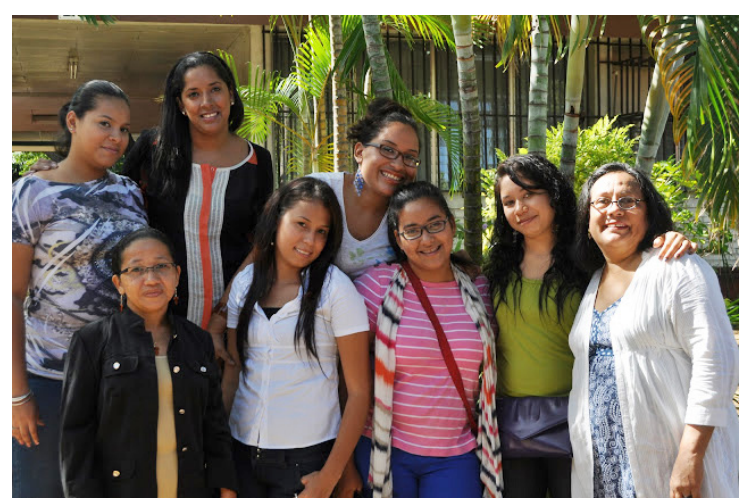

Defensas de monografías. Año académico 2012. (Foto: Departamento de Antropología)

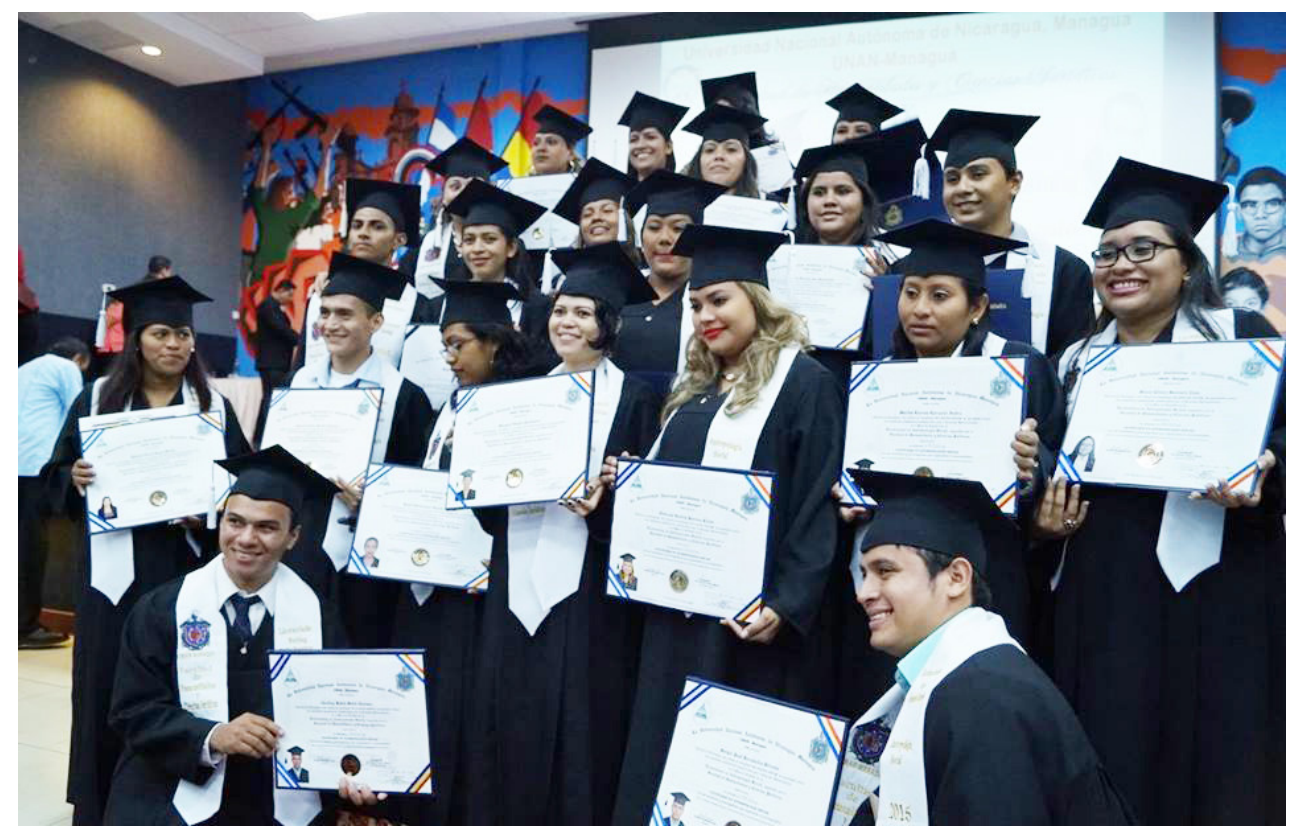

Promoción 2015.

(Foto: Departamento de Antropología) 


\section{Raíces}

Revista Nicaragüense de Antropología. Año 1 No. 1/2017

En el periodo 2012-2014 se inició la docencia de posgrado con primera cohorte de la Maestría en Antropología y Liderazgo Social, cuyo resultado es la defensa de 12 tesis. En el periodo 2015-2016 se desarrolló la segunda cohorte y se preparan 14 nuevas tesis.
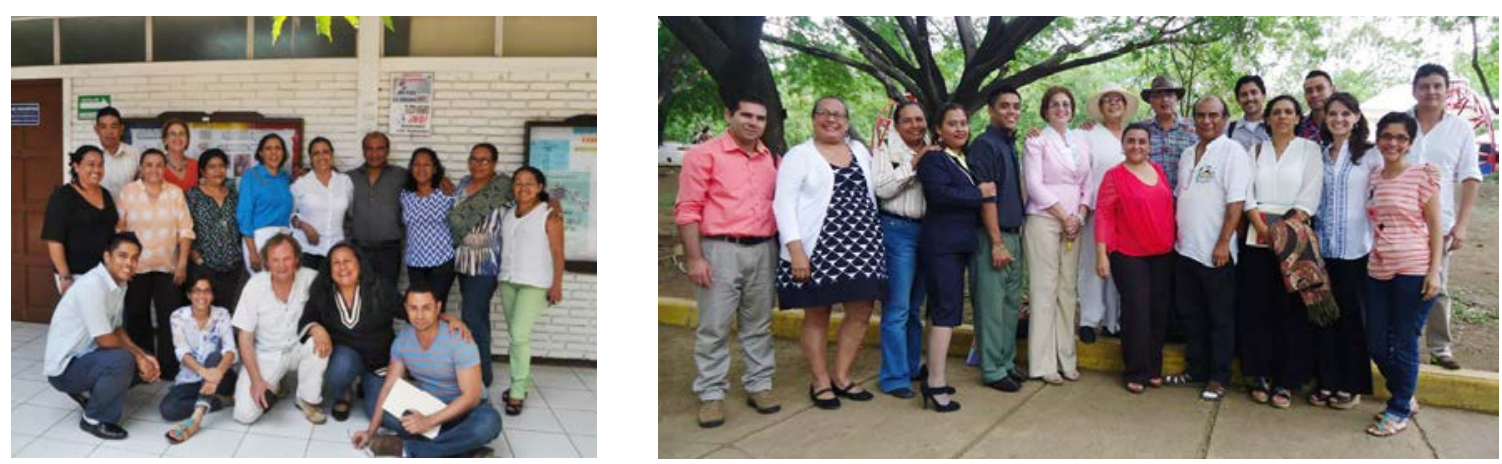

Primera Cohorte de la Maestría en Antropología y Liderazgo Social. Periodo 2012-2014 (Fotos: María Dolores Alvarez Arzate )

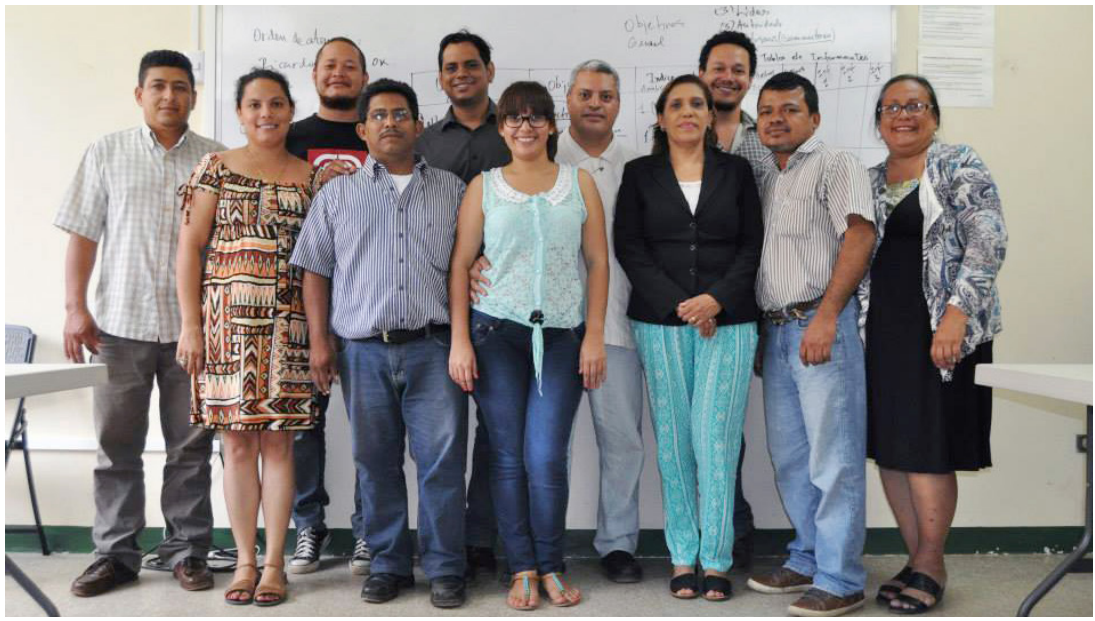

Segunda Cohorte de la Maestría en Antropología y Liderazgo Social. Periodo 2015-2016 (Fotos: María Dolores Alvarez Arzate)

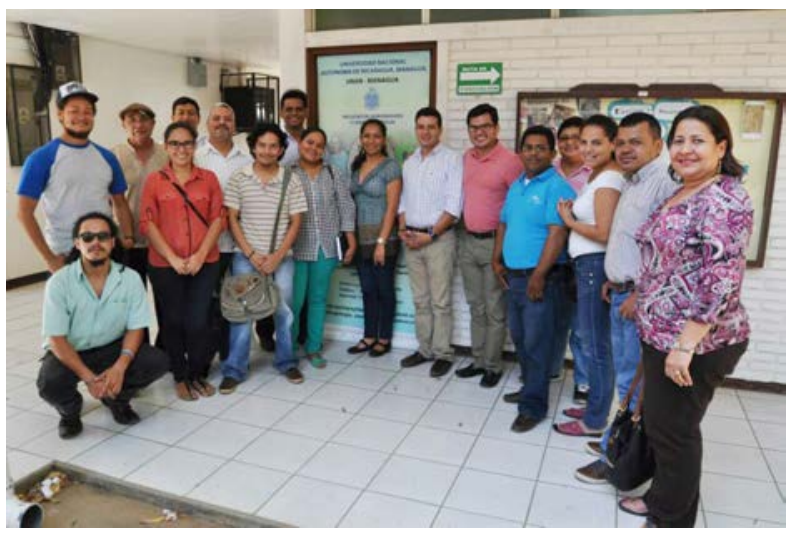


En la actualidad, el Departamento de Antropología cuenta con docentes graduados de doctorado, maestría y licenciatura en Antropología, lo que significa un aseguramiento de la especialización que exigen los tiempos actuales. Las líneas de investigación, tanto a nivel de grado como de posgrado son: Patrimonio Cultural, Desarrollo Comunitario, Dinámicas Socioculturales, Políticas Públicas y Sociales, Estudios Interdisciplinarios.

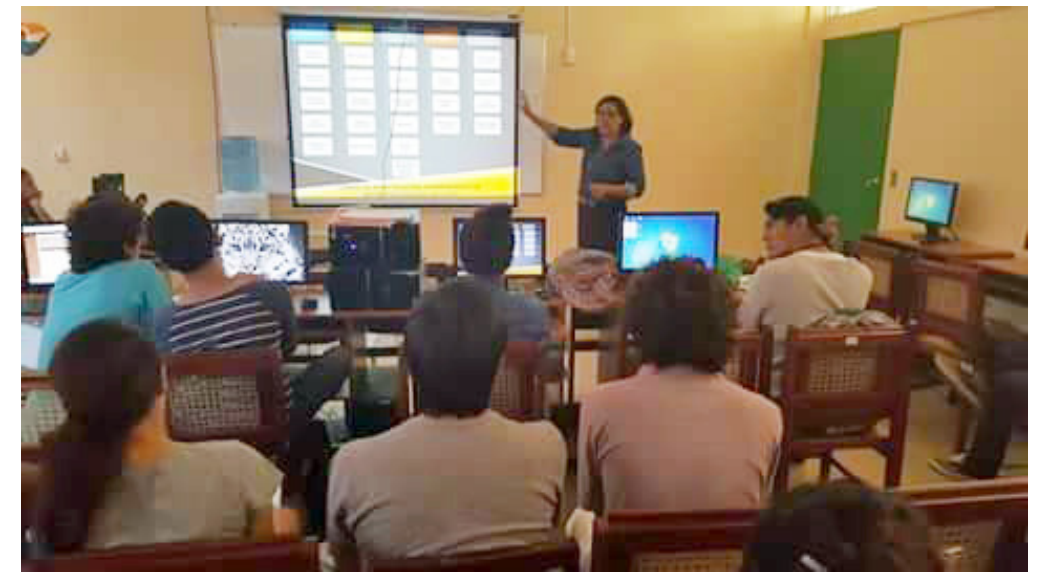

La Directora del Departamento de Antropología, Dra. Maritza Andino, presentando a los estudiantes de segundo año de la Carrera las Líneas de Investigación del Departamento (Fotos: Departamento de Antropología )

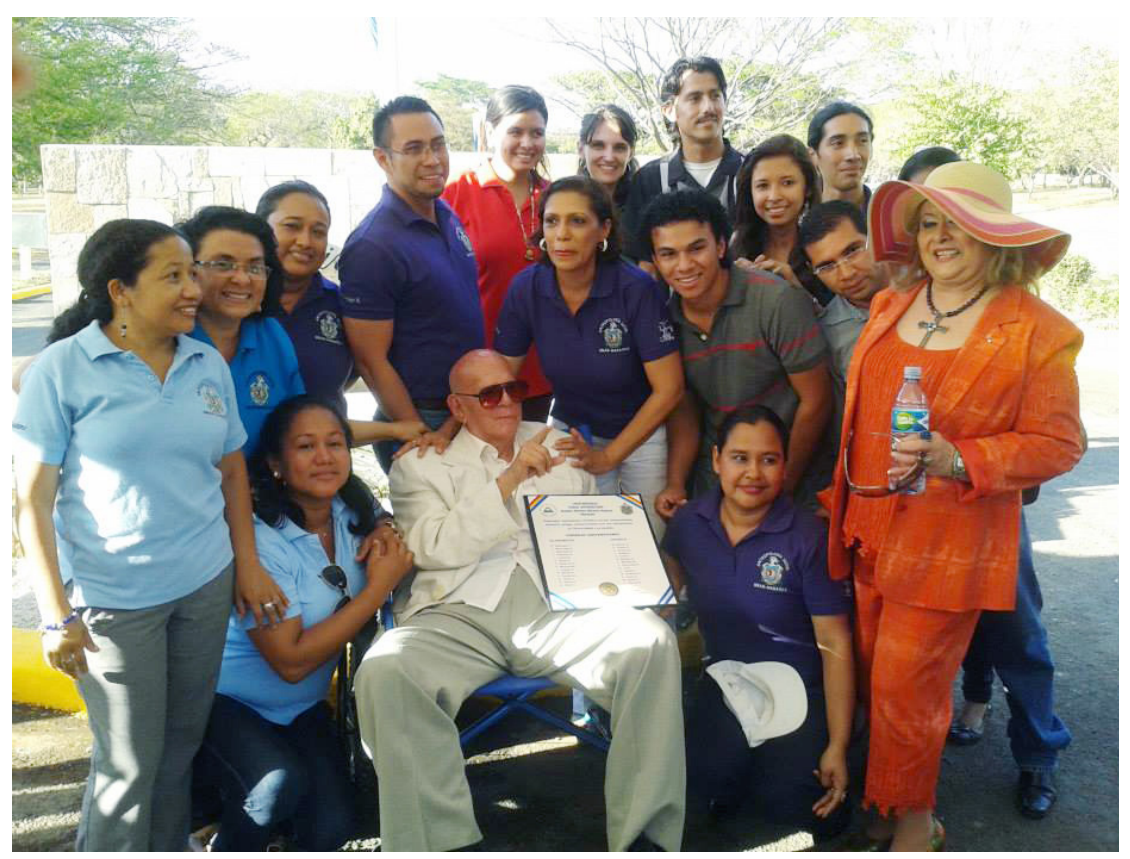

En enero de 2010, el profesor Mariano Miranda Noguera (q.e.p.d.), jubilado y miembro fundador del Departamento de Antropología, recibió la distinción de Doctor Honoris Causa en Humanidades en la UNAN Managua, nuestra Alma Mater.

Delegación del Departamento de Antropología con el profesor Mariano Miranda Noguera (q.e.p.d.), durante la inauguración del Paseo construido en su honor. UNAN-Managua, marzo de 2014

(Foto: Departamento de Antropología) 


\section{Raíces}

Se encuentran laborando en el Departamento de Antropología, tres de sus fundadoras: MSc. Gloria Argentina López Alvarado (actual Decana de la Facultad de Humanidades y Ciencias Jurídicas), Dra. Elvira Maritza Andino (Directora del Departamento de Antropología) y Dra. María Dolores Alvarez Arzate (Coordinadora de Posgrado de la Facultad de Humanidades y Ciencias Jurídicas).

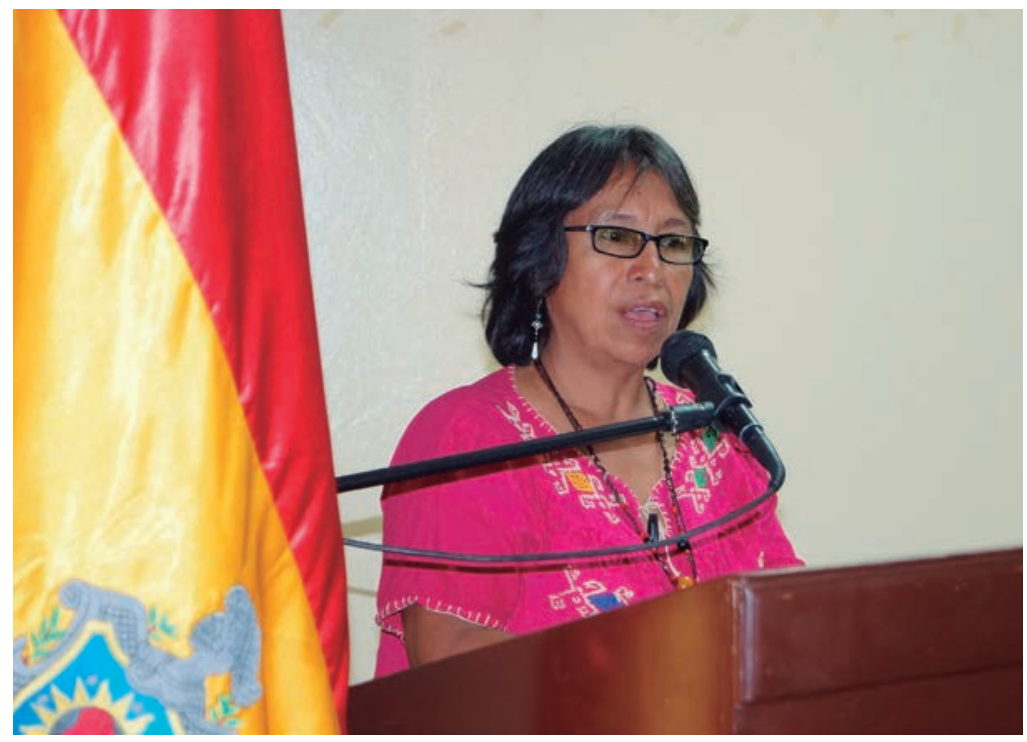

MSc. Gloria Argentina López Alvarado, Decana de la Facultad de Humanidades y Ciencias Jurídicas, UNAN-Managua (Foto: Domingo Gutiérrez)

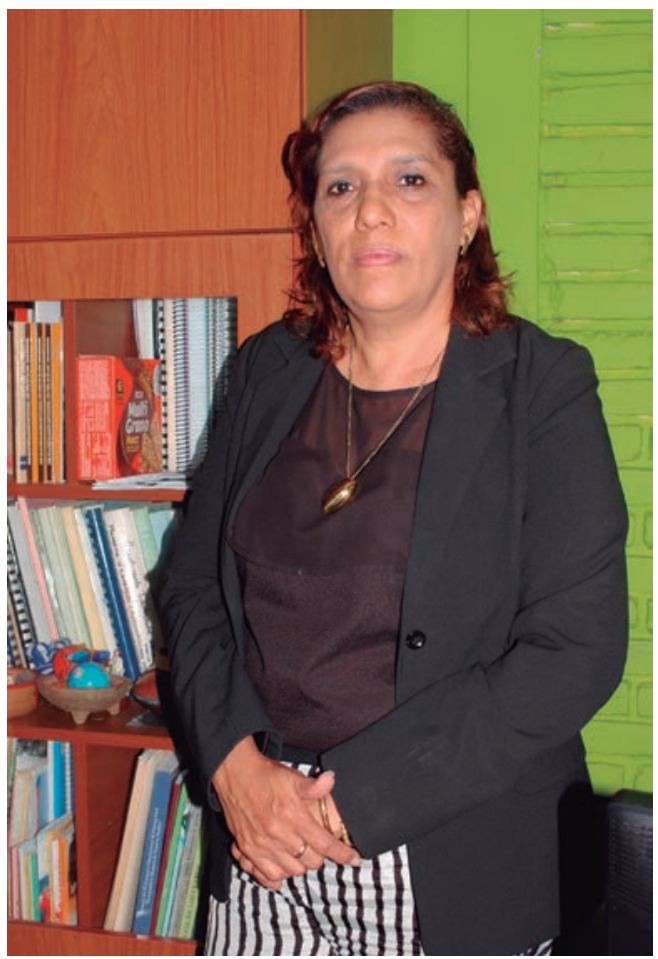

Dra. Elvira Maritza Andino, Directora del Departamento de Antropología, UNAN-Managua (Foto: Domingo Gutiérrez)

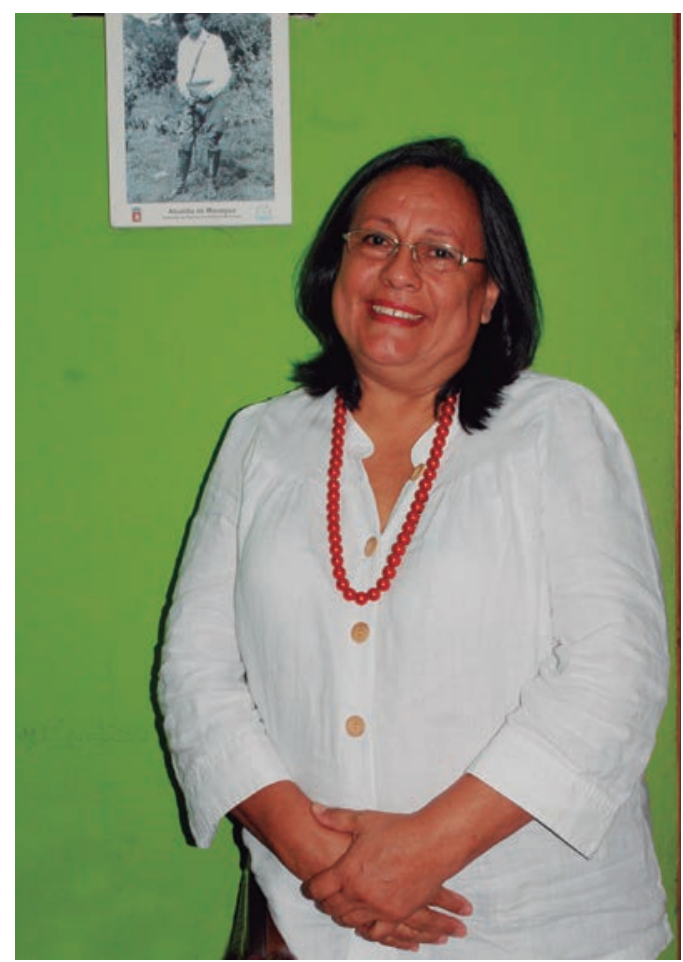

Dra. María Dolores Alvarez Arzate, Coordinadora de Posgrado de la Facultad de Humanidades y Ciencias Jurídicas, UNAN-Managua (Foto: Domingo Gutiérrez) 
La mirada de futuro apunta a consolidar y profundizar los avances alcanzados en veinte años de vida académica de la Antropología en Nicaragua que cada vez más posiciona su quehacer y compromiso con los pueblos del mundo.

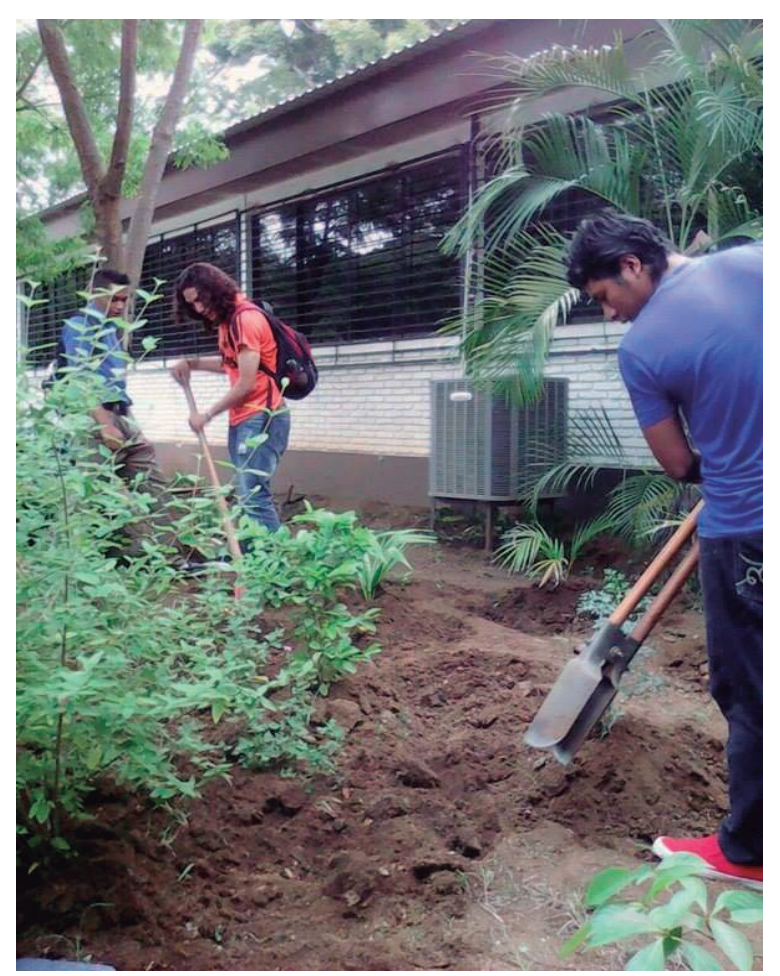

Huerto del Departamento de Antropología. Los estudiantes de la carrera siembran plantas y las cuidan en el ámbito de la asignatura de Introducción a la Antropología y Antropología Ecológica. I y II Semestre 2016. (Fotos: Departamento de Antropología)

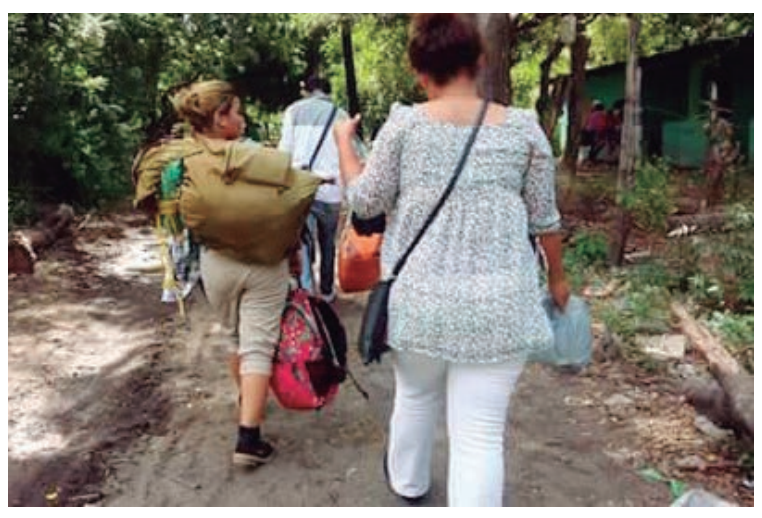

Estudiantes de segundo año de la carrera Antropología Social durante el trabajo de campo realizado en la comunidad fronteriza de Potosí, El Viejo, Chinandega. II Semestre 2016 (Fotos: Departamento de Antropología).

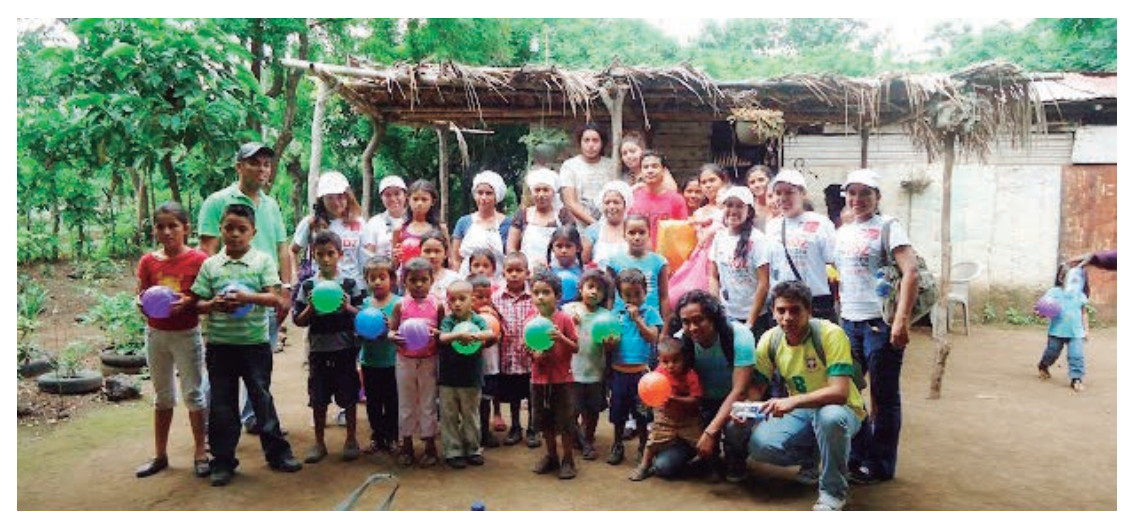

Voluntarios del Departamento de Antropología Social colaboran con la ONG Visión Mundial, apoyando en proyectos socio-educativos de comunidades rurales. Año académico 2014

(Foto: Departamento de Antropología) 


\section{Raíces}

Revista Nicaragüense de Antropología. Año 1 No. 1/2017

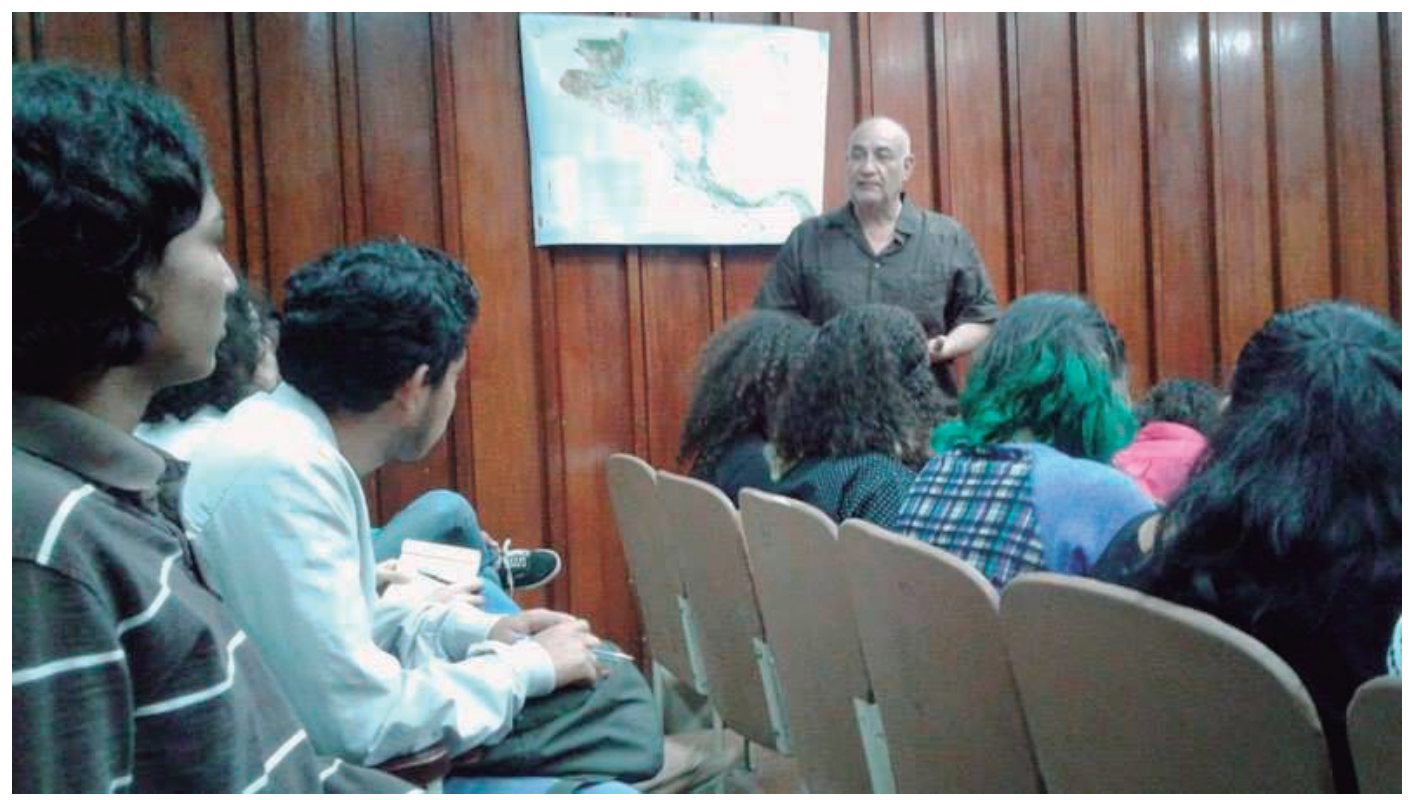

El maestro Víctor Del Cid durante una conferencia sobre los Pueblos Indígenas de Nicaragua, dirigida a los estudiantes de la Carrera. Auditorio de la Biblioteca Salomón de la Selva, UNAN-Managua. Año académico 2016 (Foto: Xavier Rodríguez)

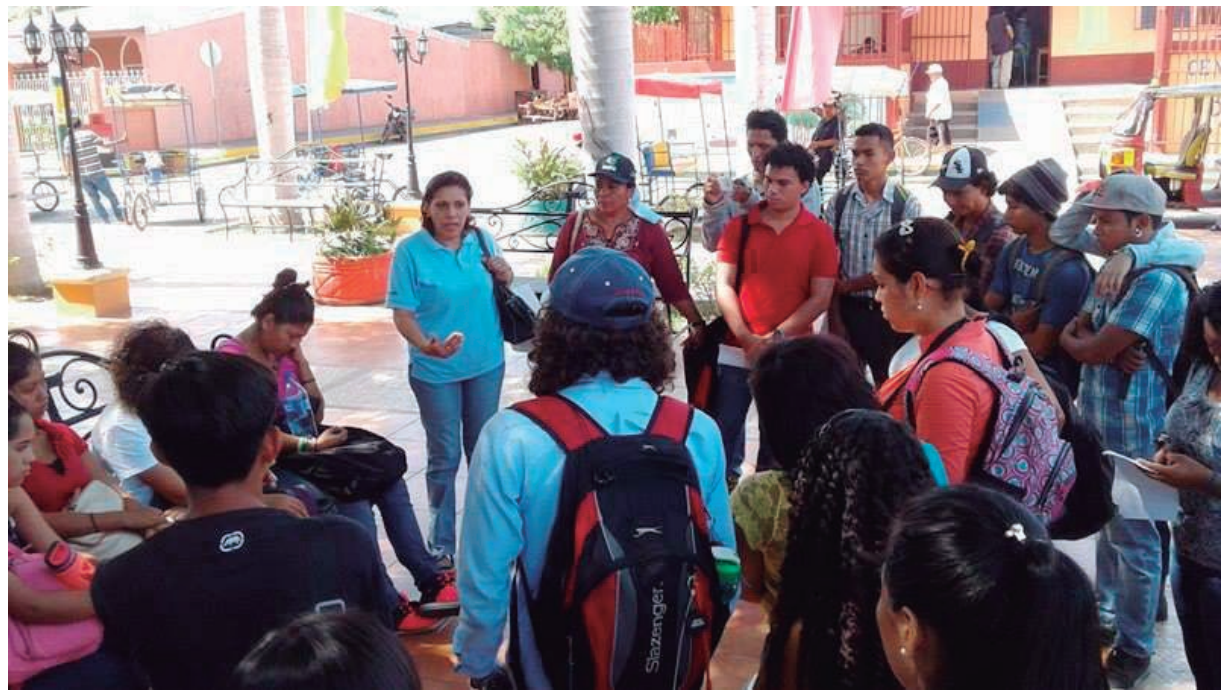

Estudiantes de primer año de la carrera Antropología Social en su primera gira de campo en Nagarote, León, acompañados por la Directora del Departamento y algunos docentes de la carrera. Una primera oportunidad para vivir cultura, aplicando el método etnográfico. I Semestre 2016 (Fotos: Xavier Rodríguez) 